\title{
Estudio Exploratorio Cualitativo acerca de la Profundización Experiencial en Julio Cortázar como Correlato a la Escritura de la obra Rayuela
}

\section{Exploratory Study Qualitative about Experiential Dipping in Julio Cortázar Correlate as the Hopscotch Writing Work}

\author{
Cristian Venegas Ahumada ${ }^{1}$ \\ Universidad Santo Tomás de Chile
}

(Recepción: Octubre 2005 - Aceptación: Noviembre 2005)

\begin{abstract}
El objetivo es describir la profundización experiencial de Cortázar, durante el período de creación de su obra Rayuela (27 de Junio de 1959 al 26 de Julio de 1963), considerando las cartas enviadas por el autor. Se usó un análisis de contenido con 7 categorías incluidas en la Escala Experiencial Forma Explicativa de Gendlin, aplicadas a párrafos epistolares con mención implícita o explícita a la obra Rayuela (unidad de análisis). Dos jueces independientes clasificaron el nivel experiencial para cada párrafo. De 139 párrafos, $87,77 \%$ fue concordante y $12,23 \%$ discordante. El nivel: IV $43,65 \%$, III 18,25\%, II 17,46\%, I 13,49\%, VII 3,96\%, VI 2,38\% y V $0,79 \%$. Estos resultados indican que Cortázar, en el contacto con su sensación-sentida, expresa fluidamente uno o muchos sentimientos con significados de autoimagen (contenido) y comunica lo que es él mismo (forma). La elevada concordancia entre los jueces indica que la escala posee buena confiabilidad; posee validez para definir comportamientos verbales que ocurren en un contexto distinto al terapéutico y oral.

Palabras clave: Nivel de profundización experiencial, sensación-sentida, Escala Experiencial Forma Explicativa.

The objective is to describe phenomenological of Cortázar's subjectivity correlate as the Hopscotch writing work considering the letters sent for the author in the creation period (27 June of 1959 to the 26 July of 1963).To used contents of analysis with 7 categories included in the Experience Scale Explanative Form of Gendlin to apply paragraphs with implicit or explicit contents about Hopscotch (analysis unity), describing so the experiential dipping. Two independents judges classified the experiential dipping of level for each paragraph. Of 139 paragraphs, $87,77 \%$ accords and $12,23 \%$ discordance's. The level: IV $43,65 \%$, III $18,25 \%$, II $17,46 \%$, I $13,49 \%$, VII 3,96\%, VI 2,38\% y V 0,79\%. This results indicate that Cortázar in the contact with your felt-sense, express fluency one or much sentiments with auto-image of meaning (form) and express authenticity (contents). The high concordance between judgments indicate confiavility of the scale; possess validity for describe verbal conducts writings in none clinic context.
\end{abstract}

Key words: Experiential dipping of level, felt-sense, Experiencing Scale Explanative Form.

\section{Fundamentación Teórica}

Cuando una persona efectúa la narración de una experiencia, sus palabras permiten vislumbrar aspectos susceptibles de modificarse a lo largo del relato, y que son dicotómicos: implicación personal / ausencia de implicación personal, presencia / ausencia de emociones y/o sentimientos (Gendlin, 1997). Sin embargo, ¿cómo se puede explicar que alguien muestre estos cambios cualitativos? Para responder a la interrogante, la Teoría Experiencial de Eugene

1 Licenciado en Psicología, Psicólogo, Universidad Nacional Andrés Bello [UNAB], Campus Viña del Mar, Chile; Magíster en Psicología Social Mención en Psicología Jurídica, Universidad de Valparaíso [UV], Chile. E-mail: cristianvenegasahumada@yahoo.es
T. Gendlin ${ }^{2}$ sostiene que las diferencias se dan por el grado de contacto que una persona establece con su sensación-sentida, la cual puede definirse como:

“[...] una sensación física compleja e interna de algún aspecto de la propia vida o situación o huella de la realidad en nosotros [...]. Es el punto limitrofe que el pensamiento humano todavia no ha atravesado (en donde el nuevo y posterior experienciar todavía no ha ocurrido) [...]. Esto ocurre así porque las palabras nos vienen a partir de este experienciar, y su articulación y sintaxis también se ve ordenada y reordenada una y otra vez por este experienciar" (Gendlin, 1997, p. 28-29).

2 (1926-). Filósofo vienés, Doctor en Filosofía y psicoterapeuta Humanista. 
Para describir la diversidad cualitativa en la narración de una experiencia, la Escala Experiencial (Gendlin, 1969) dispone de 7 niveles, que dan cuenta de la profundización experiencial, es decir, de la cualidad y el grado de contacto con la sensación-sentida. A partir de ella surgen nuevos pensamientos y sentimientos, a los cuales no se puede acceder de ninguna otra manera, estableciendo así la base para la creatividad (Gendlin, 1981).

La Teoría Experiencial se fundamenta en la corriente de la Filosofia denominada Fenomenología, la cual, desde un punto de vista epistemológico, sostiene: "lo que el fenómeno es, lo es absolutamente, pues se devela como es. El fenómeno puede ser estudiado y descrito en tanto que tal, pues es absolutamente indicativo de sí mismo" (Sartre, 1943, p. 12).

A partir de este contexto teórico, se ha considerado plausible describir el proceso de profundización experiencial en Julio Cortázar a partir de las cartas referidas a Rayuela, durante el período de su creación; pues estas fuentes nos comunican la subjetividad del autor asociada a la novela (Percival, 1987; Segre, 1985).

Como corolario, la presente investigación es un estudio fenomenológico, porque:

“[...] es un intento de representar o describir adecuadamente la existencia de una persona mediante una fidelidad a la cualidad misma y a la experiencia de esa existencia. El punto de vista, la terminología, el énfasis en un estudio fenomenológico es el del propio sujeto experienciante" (Van Dusen, 1975, p. 99).

\section{Objetivos}

\section{Objetivos generales:}

1. Realizar un estudio cualitativo para describir la profundización experiencial en Julio Cortázar como correlato a la escritura de Rayuela.

2. Establecer la relación que existe entre profundización experiencialy acto creativo.

3. Aportar al desarrollo del grado de pertinencia que puede tener la Escala Experiencial de Gendlin en un ámbito no clínico.

4. Aportar al desarrollo de un enfoque Humanista para el estudio de la profundización experiencial como correlato al acto creativo en Literatura.
Objetivos especificos:

1.1 Identificar los niveles de profundización experiencial que muestra Julio Cortázar en las cartas referidas a Rayuela que escribe en el período que va desde el 27 de Junio de 1959 al 26 de Julio de 1963.

2.1 Establecer cómo se relacionan teóricamente la profundización experiencial y el acto creativo.

3.1 Validar la consideración hipotética que dice: "La profundización experiencial es un correlato del acto creativo de Rayueld".

4.1 Extrapolar la Escala Experiencial de Eugene T. Gendlin a la experiencia de Julio Cortázar como correlato de la escritura de Rayuela.

\section{Formulación del problema}

¿Cuál es el nivel de profundización experiencial logrado por Julio Cortázar como correlato al escribir su obra Rayuela, basándose en las cartas enviadas por el autor en el período que va desde el 27 de Junio de 1959 al 26 de Julio de 1963 ?

\section{Marco metodológico}

\section{Tipo de investigación}

La investigación es de tipo exploratorio, porque "[...] el objetivo es examinar un tema o problema de investigación poco estudiado o que no ha sido abordado antes" (Hernández, Fernández \& Baptista, 1991, p. 58). Desde el paradigma experiencial de Eugene T. Gendlin, no ha sido posible encontrar ninguna investigación ${ }^{3}$ en donde se haya aplicado la Escala Experiencial para establecer los niveles de profundización experiencial alcanzados por algún escritor, relacionándolos con el acto creativo de alguna obra literaria.

\section{Diseño}

De acuerdo con la nomenclatura tradicional, el diseño de la investigación es no experimental, transeccional o transversal, de corte cualitativo, basado en el caso único de tipo Intrínseco,

\footnotetext{
3 A partir de una búsqueda mediante Internet en Chile: Base de Datos del Colegio de Psicólogos, catálogos de Universidades y Revistas de Psicología. Se ha abarcado el período 1993-2005.
} 
porque el interés es llegar a comprender exhaustivamente la particular subjetividad de Cortázar (Stake, 1995).

\section{Técnica de investigación}

Se utilizará el Análisis de Contenido [AC], definido como "[...] una técnica de investigación destinada a formular, a partir de ciertos datos, inferencias reproducibles y válidas que puedan aplicarse a sus contextos "(Krippendorff, 1980 , p. 28). Para el presente caso se entenderá por contexto el proceso de escritura de la obra Rayuela. Por tanto, se intenta establecer inferencias que pudieran eventualmente asociar el Nivel de Profundización Experiencial, porcentualmente mayor, con la escritura de la novela, por tanto con la creatividad del autor.

Para el presente estudio, el AC se realizará con categorías a priori, definidas a partir de cada uno de los 7 niveles de la Escala Experiencial Forma Explicativa de Eugene T. Gendlin.

\section{Procedimientos}

La totalidad de las cartas escritas por Julio Cortázar se encuentran contenidas de modo íntegro en 3 tomos editados por Bernárdez (2000), que comprenden distintos períodos:

Tomo 1 (1937-1963)

Tomo 2 (1964-1968)

Tomo 3 (1969-1983)

1 Considerando que el interés de esta investigación era realizar una descripción fenomenológica de la profundización experiencial en Julio Cortázar como correlato a la escritura de la obra Rayuela, publicada por primera vez en el año 1963, se trabajó sólo con el tomo 1 (1937-1963).

2 Como primera tarea se procedió a leer todas las cartas que conforman dicho volumen, considerándoselas como fuente original, con el propósito de identificar todas aquellas que contenían una referencia implícita o explícita a la obra Rayuela.

3 Dentro de la carta, se le asignó a cada párrafo que contenía una referencia a la obra Rayuela un número, siguiendo un orden correlativo que partía con el "P-001". Como ejemplo del procedimiento, podemos decir que si en una carta se llegaba hasta "P-003", al encontrar el próximo párrafo en satisfacer el criterio se codificó como "P-004", y así sucesivamente, hasta alcanzar un total de 139 párrafos.

4 La unidad de análisis fueron los párrafos seleccionados según el procedimiento descrito precedentemente.

5 A continuación se transcribieron los párrafos de modo literal, sacándolos del contexto de la carta.

6 El motivo de tal procedimiento (punto 5) se justifica si se considera que sólo los párrafos donde se habla de Rayuela (punto 4) son los únicos que tienen relevancia para el estudio, no importando las referencias a otras temáticas.

7 Se confeccionaron dos juegos con los párrafos elegidos con el propósito de que estos fueran los textos a analizar por los jueces del estudio ${ }^{4}$.

8 Cada uno de los jueces analizó los párrafos extraídos y transcritos, procediendo a clasificarlos considerando su contenido textual.

9 La clasificación de los párrafos se hizo atendiendo a la correspondencia de su texto con las exhaustivas descripciones de los siete niveles establecidos por E. T. Gendlin en la Forma Explicativa de la Escala Experiencial.

10 Se situó cada párrafo en un nivel de la Escala, señalando el criterio por el cual es incluido en el nivel correspondiente. Para tal efecto se citó textualmente el fragmento de la escala experiencial que lograba describir el contenido del párrafo.

$11 \mathrm{El}$ procedimiento llevado a cabo según lo expuesto en el punto 10 fue realizado de modo independiente y paralelo por ambos jueces.

12 Se compararon las clasificaciones otorgadas por ambos jueces a los párrafos según la adjudicación de éstos a cada uno de los siete niveles de la escala.

13 Luego de analizar con detalle los criterios que llevaron a los jueces a resultados divergentes, se concordó, cuando se consideró pertinente, la reclasificación de alguno de ellos en uno de los siete niveles experienciales de la Escala.

4 Leonardo R. Villarroel Illic, Psicólogo Clínico Humanista de orientación gendliniana. 
5. Descripción del instrumento utilizado: "Escala Experiencial Forma Explicativa" de Eugene T. Gendlin

La Escala fue diseñada a partir de grabaciones terapéuticas, con el objetivo de definir la cualidad y el grado de contacto con la experiencia-sentida, accediendo a ella a partir de los comportamientos verbales (Gendlin, 1969b, 1997). Estos últimos pueden ser clasificados en alguno de los 7 niveles que constituyen la Escala. Esta posee dos formas: una "Explicativa", donde se describen con gran detalle los criterios de inclusión cualitativos para cada nivel y una "Abreviada", que consiste en una tabla resumida de dichos criterios, la cual se muestra a continuación.

Cuadro No 1: Forma Abreviada de la Escala Experiencial

\begin{tabular}{|c|c|c|}
\hline Nivel & Contenido & Forma \\
\hline 1 & $\begin{array}{l}\text { No se usa referencia alguna. Narración de eventos de forma } \\
\text { pública y desde afuera. Negativa de implicación personal. }\end{array}$ & $\begin{array}{l}\text { Inexistencia de una impli- } \\
\text { cación personal. }\end{array}$ \\
\hline 2 & $\begin{array}{l}\text { Los referentes personales se utilizan para establecer que se tra- } \\
\text { ta de su historia. }\end{array}$ & $\begin{array}{l}\text { Implicación personal en la } \\
\text { narración. }\end{array}$ \\
\hline 3 & $\begin{array}{l}\text { La utilización y expresión de emociones se realiza tangencial- } \\
\text { mente, a modo de paréntesis en la narración. Aun así, los senti- } \\
\text { mientos personales todavía están: (a) completamente atados a } \\
\text { las situaciones en las que aparecen. (b) Sin elaborar en térmi- } \\
\text { nos de significado personal más profundo o significación. }\end{array}$ & $\begin{array}{l}\text { Implicación personal más } \\
\text { allá del contenido específi- } \\
\text { co, pero sin conseguir sig- } \\
\text { nificados más profundos. }\end{array}$ \\
\hline 4 & $\begin{array}{l}\text { Se da de distintas formas: Expresión fluida de muchos senti- } \\
\text { mientos; expresión de un solo sentimiento, en el que el cliente } \\
\text { se toma su tiempo para elaborarlo en términos de significado } \\
\text { de autoimagen; expresión o comunicación de que el sentimien- } \\
\text { to existe, pero se necesita ayuda para expresarlo mejor. }\end{array}$ & $\begin{array}{l}\text { La persona comunica lo que } \\
\text { es ella misma. }\end{array}$ \\
\hline 5 & $\begin{array}{l}\text { Exploración de: (a) una sola situación relevante a la autoimagen, } \\
\text { que a su vez implica muchos sentimientos y consecuentes rela- } \\
\text { ciones, o también la descripción de un área de sentimientos con } \\
\text { el significado personal consecuente; (b) examen y exploración } \\
\text { de varias situaciones y sus puntos en común. }\end{array}$ & $\begin{array}{l}\text { Definición del problema en } \\
\text { términos de sentimientos e } \\
\text { intento de exploración de } \\
\text { los mismos. }\end{array}$ \\
\hline 6 & $\begin{array}{l}\text { Los sentimientos se integran. Existencia de asociaciones entre } \\
\text { sentimientos y los significados personales. }\end{array}$ & $\begin{array}{l}\text { El cliente es capaz de llegar } \\
\text { a conclusiones surgidas a } \\
\text { raíz de intuiciones produci- } \\
\text { das por el hallazgo de signi- } \\
\text { ficados en los sentimientos. }\end{array}$ \\
\hline 7 & $\begin{array}{l}\text { El cliente ya no necesita la narración como punto de partida. Ya } \\
\text { es capaz de moverse libremente a través de sus sentimientos. Ya } \\
\text { no existe dificultad alguna en relacionar lo que él dice con los } \\
\text { significados que sus acciones y pensamientos tienen para él. Se } \\
\text { mueve fácilmente a través de sus referencias interiores y es ca- } \\
\text { paz de integrarlas dentro de su marco de referencia existencial. }\end{array}$ & $\begin{array}{l}\text { Desde un marco existencial } \\
\text { de referencia, se produce } \\
\text { una libertad interior de mo- } \\
\text { vimiento en cuanto a los } \\
\text { sentimientos y sus signifi- } \\
\text { cados. }\end{array}$ \\
\hline
\end{tabular}


Forma Explicativa de la Escala Experiencial de Eugene T. Gendlin.

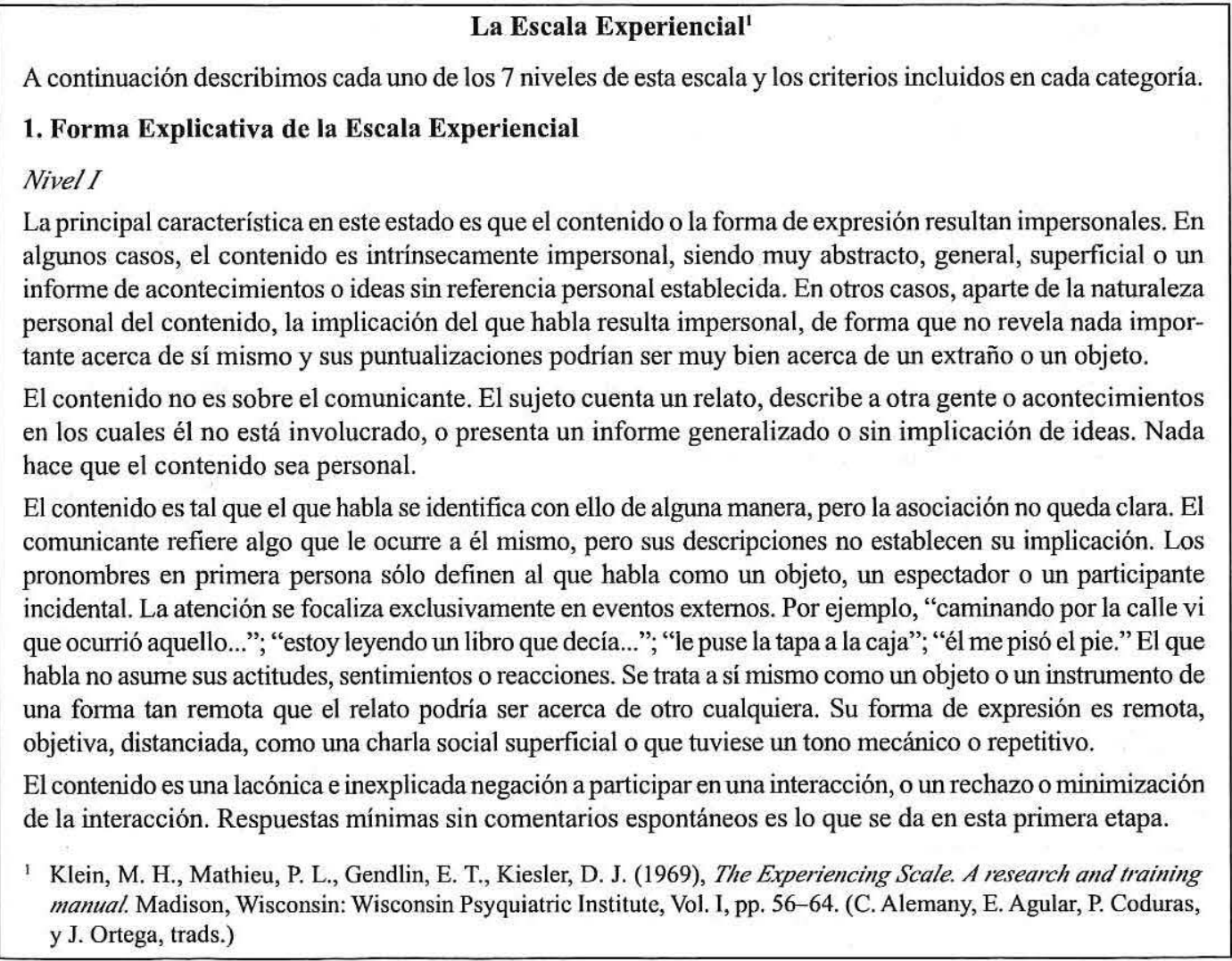

\section{Nivel II}

La asociación entre el que habla y el contenido es explícita. El comunicante es ya la figura central de la narración o su interés resulta claro. La implicación del que habla, sin embargo, no va más allá de la situación específica o el contenido. Todos los comentarios, asociaciones, reacciones y puntualizaciones sirven al relato o idea para hacerse entender, pero no refieren o definen los sentimientos del comunicante.

El contenido es una narración de eventos en los cuales el comunicante no está personalmente implicado. Sus puntualizaciones y asociaciones se refieren a facetas externas de la narrativa, otra gente, los eventos, objetos, las acciones del que habla; no proporcionan sus reacciones interiores o perspectiva. Si la narrativa incluye los pensamientos del comunicante, opiniones, deseos o actitudes, éstos sólo describen al mismo intelectual o superficialmente. Algunos refieren a las ideas y pensamientos como si fueran sentimientos. Ejemplo: "Siento que soy un buen granjero"; "siento que la gente debería ser más considerada". Si términos como "opino" o "deseo" pueden sustituirse por "siento" sin cambiar el sentido, la puntualización hecha está en el nivel II.

Los eventos narrados son impersonales, pero el que habla especifica explícitamente que el contenido es importante para él. Por ejemplo, expresa interés en, o evalúa, un evento, pero no muestra la forma o la cantidad de su interés, o lo que le concierne.

El contenido es una auto-descripción que resulta superficial, abstracta, generalizada o intelectualizada. No se hace referencia a los sentimientos del comunicante o a su perspectiva interna. El discurso presenta las ideas, actitudes, opiniones, juicios morales, deseos, preferencias, aspiraciones o capacidades que describe el comunicante desde una perspectiva externa o periférica. Uno lo percibe como ajeno.

El contenido revela los sentimientos y reacciones del que habla implícitamente, pero no explícitamente. Si el comunicante está afectado emocionalmente, resulta evidente por su forma de actuar, no por sus palabras. Si el contenido es del tipo que ordinariamente pudiera ser de significación personal, el comunicante no lo dice. Si el comunicante comunica sus sentimientos, les da un trato abstracto, impersonal, como objetos, o se los atribuye a otros. Pronombres en tercera persona, especialmente "uno siente", son indicativos de despersonalización.

El contenido es una retahíla de sueño, fantasía, alucinación o asociación libre. Este puede ser tratado como eventos narrados o externos. Están en la etapa II si lo subrayado por el que habla lo asocia a sí mismo con lo contado, pero no le imprime sus reacciones de sentimientos. 


\section{CRISTIAN VENEGAS}

\section{Nivel III}

El contenido es una narración o descripción del comunicante en términos externos o conductuales, con comentarios añadidos de sus sentimientos o experiencias privadas. Estas puntualizaciones son limitadas a los eventos o situaciones descritos, dando a la narración un toque personal sin descripción del comunicante más ampliamente. Son también del nivel III las autodescripciones que se circunscriben a situaciones específicas o roles.

El contenido es una narración de eventos o descripción de un aspecto del medio ambiente del comunicante (pasado, presente o futuro), con puntualizaciones personales entre paréntesis, dado de las formas siguientes:

1. El sentimiento del comunicante se da al mismo tiempo que el acontecimiento o retrasado respecto de él. Por ejemplo, "él no me hizo volver y me enfadé", o "él no me hizo volver; pensando en ello ahora, me enfado".

2. Se da el significado personal o aplicaciones en la situación relacionándola con la experiencia privada del comunicante. Por ejemplo, "esto me suena a ser regañado como un chaval"; "era uno de esos extraños estados de ánimo que me vienen cuando estoy cansado".

3. El estado de darse cuenta del comunicante ocurre al mismo tiempo que el evento. Tales expresiones incluyen detalles de motivos, concienciaciones, percepciones privadas o asunciones que quedan limitadas al evento. Por ejemplo, "sabía entonces que estaba reaccionando demasiado enérgicamente"; "era consciente de que buscaba defenderme"; "lo hice aun sabiendo que quedaba como un tonto". Materiales de sueños, alucinaciones, fantasías y asociaciones libres pueden tratarse como narraciones; están en el nivel III si se mencionan los sentimientos.

El contenido es una auto-descripción de aspectos circunscritos al estilo de vida del comunicante, o su rol o sus sentimientos y reacciones presentados sólo en términos conductuales. El comunicante puede, por ejemplo, describir cómo funciona él como padre o en su trabajo, o decir cómo se comporta cuando está enfadado. Las puntualizaciones personales enriquecen la descripción de la situación o reacción a ello, pero están limitadas al contexto inmediato.

En respuesta a cuestiones directas, el comunicante dice cómo son o fueron sus sentimientos. Las palabras del entrevistador no son necesarias para identificar el sentimiento.

\section{Nivel IV}

El contenido es una presentación clara de los sentimientos del comunicante, dando una perspectiva personal, interna, de los sentimientos acerca de sí mismo. Los sentimientos o la experiencia de eventos, más que los eventos mismos, son el objeto del discurso. Atendiendo a ello, y presentando esta experienciación, el que habla comunica lo que le parece que es él. Estas visiones interiores son presentadas, enumeradas o descritas, pero no están interrelacionadas o usadas como base para un auto-examen sistemático o formulación.

El contenido inicial es una situación específica que resulta ampliada y profundizada por las auto-referencias del comunicante para mostrar lo que él es de forma más general o más personal. El comunicante debe describir sus sentimientos con gran detalle, referir a sentimientos mientras estos ocurren en un rango de situaciones, proveer reacciones personales a sentimientos específicos o reacciones relacionadas con su propia auto-imagen. Los sentimientos pueden ser respuestas inmediatas o respuestas recordadas de situaciones pasadas. El comentario auto-descriptivo debe versar sobre aspectos internos y personales del que habla, no con evaluaciones morales o características externas o conductuales.

El contenido es un relato dicho desde un punto de vista completamente personal. Los detalles de sentimientos, reacciones y asunciones son integrados en la narrativa, de forma que lo que emerge es un cuadro detallado de la experiencia personal del comunicante sobre los eventos.

El contenido es una auto-caracterización en la cual el que habla dice su perspectiva personal. Al hablar de sí mismo hace explícitos sus sentimientos, personalidad, asunciones, motivos, fines y percepciones privadas. Al revelar estas partes internas de sí mismo, el comunicante da una pintura detallada de uno o más de sus estados de ser. El material presentado no es analizado o interrelacionado. El uso de términos abstractos o jergas para describir elementos de personalidad debe ser ampliado con algún detalle interno para homologarse al nivel IV. Por ejemplo, la frase "mi ego estaba dividido" podría necesitar elaboración, tal como "sentía como si no fuese nada, que nadie tendría que darse cuenta de mí." 
Nivel V

El contenido es una exploración con propósito de los sentimientos y la experienciación del comunicante. Se dan dos componentes necesariamente. Primero, el comunicante debe plantear o definir un problema o una proposición acerca de sí mismo explícitamente en términos de sentimientos. El problema o proposición puede recoger el origen, secuencia o implicaciones de sentimientos, o sentimientos relacionados con otros procesos privados. Segundo, el comunicante debe explorar o trabajar con un problema de una forma personal. La exploración o elaboración debe estar claramente relacionada con la proposición inicial, y debe contener referencias internas de forma que funcione expandiendo el darse cuenta del comunicante sobre la experienciación. Ambos componentes, problema y elaboración, deben estar presentes.

La proposición o problema debe estar dada clara o contundentemente, y pude incluir referencias a sentimientos o experiencia personales sobre la temática. Si las bases internas del problema son débiles, como referencias a conductas indeseadas o estilos indeseados, proposiciones sobre los precipitantes externos de la conducta o sentimientos, o presentación de secuencias temporales de sentimientos, entonces la exploración o elaboración debe hacerse extensiva a referencias internas. Debe quedar claro que el comunicante está localizando en su experiencia interna más que simplemente justificando su conducta.

El problema o hipótesis acerca de si debe estar orientado a sentimientos, reacciones privadas o asunciones básicas de la auto-imagen. Puede presentarse de distintas formas:

1. Un sentimiento, reacción o proceso interno, y en algunos casos un patrón de conducta, puede ser definido como problemático en sí; por ejemplo, "mi tristeza es el problema" o "ipor qué estoy tan enfadado?".

2. El comunicante puede buscar si tiene, o en qué sentido tiene, un sentimiento específico; no "¿qué siento?", lo cual podría ser tres o cuatro cosas, sino “¿realmente me siento enfadado?”, o “¿cómo estoy de enfadado realmente?"

3. El problema o proposición puede ser definido en términos de implicaciones personales, tipos de relación y ramificaciones internas de un sentimiento, incluyendo sus orígenes o causas, su lugar en una secuencia temporal de sentimientos y eventos internos, su forma de expresión o sus aplicaciones personales y privadas. Por ejemplo: ¿me enfado cuando me siento inepto?" o "el enfadarme significa que he perdido el control de mí", o "me enfado como solía hacerlo mi madre".

4. Sentimientos, reacciones y procesos internos pueden compararse.

Todos los problemas o frases acerca de sí deben ser explorados o elaborados con referencias internas. Ejemplos o ilustraciones pueden mostrar cómo el comunicante experiencia el problema o proposición en etapas diferentes o a veces distintas; si se da, la pertenencia de la ilustración al problema puede ser explícita. El problema o proposición debe estar relacionado con otros procesos internos o reacciones. Como alternativa, a través de hipótesis, especulación o analogía, el comunicante clarifica la naturaleza o implicación privada del problema central, su causa o ramificaciones.

En esta etapa V, el comunicante está explorando o probando una hipótesis acerca de su experienciación. Mientras que defina el objeto de ese proceso claramente con referencias internas, su forma puede ser condicional, tentativa, vacilante $\mathrm{o}$ indagante.

Nivel $V I$

El contenido es una síntesis de sentimientos y experiencias bastante accesibles, reconocidas de forma nueva o realizadas más plenamente, en orden a producir estructuras significativas personalmente o para resolver temas. Los sentimientos más inmediatos del comunicante son integrados con sus conclusiones sobre sus tareas internas. Él comunica una auto-experienciación nueva o enriquecida, y el impacto experiencial de los cambios en sus actitudes o sentimientos acerca de sí mismo. El objeto del asunto concierne al experienciar presente y emergente del comunicante. Su asunto puede reflejar cambios o intuiciones en el momento en que ocurren. Estas son elaboradas verbalmente con detalle. Aparte del contenido específico, el comunicante expresa un sentido de involucración inmediata en un tema fondeado experiencialmente, con evidencia de su resolución o aceptación.

Los sentimientos involucrados deben ser presentados vivida, plena o concretamente. Los sentimientos anteriores o los cambios sucedidos en sentimientos anteriores son presentados vívidamente o revividos como parte de la experiencia actual del comunicante. 
El proceso de estructuración relaciona estos eventos sentidos actualmente con otros aspectos de la perspectiva privada del comunicante. Así, un sentimiento puede estar relacionado con la auto-imagen del comunicante, sus percepciones privadas, motivos, asunciones, relacionadas con otro sentimiento, o con facetas más externas de la vida del comunicante, como su conducta. En cada caso, la naturaleza del tipo de relación debe ser definida de forma que los detalles de cómo el comunicante trabaja dentro de sí y el impacto de los cambios internos queden revelados. Esto no consiste meramente en la existencia de un tipo de relación, ni en una lista de secuencias de sentimientos y de experiencias internas, sino que la naturaleza y la cualidad de esa asociación se hacen claras.

El proceso sintético y estructurado lleva a una experiencia interior significativa personal y nueva, o resuelve un asunto. Como resultado de trabajar con sus sentimientos y otros aspectos de su perspectiva privada y explorando su relación con los demás, el comunicante tiene experiencias internas nuevas. Estas pueden ser de nuevos sentimientos o sentimientos cambiados, como cuando el comunicante dice: "Ahora estoy comenzando a ver que mi sentimiento de culpa está causado por mis ideas acerca del trabajo y me hace estar mucho menos angustiado al sentir esa culpa. ¡Qué descanso!". 0, también, un tema puede resolverse: “¿Sabes?, siempre he guardado mis enfados en un bote porque he sentido miedo de perder el control de mí mismo. Ahora me doy cuenta de que no sería tan malo si lo hago. Parece como si hubiera gritado o expulsado algo, eso es todo". Si el comunicante comienza con un problema externo concreto, los sentimientos relativos a ello deben ser presentados como parte de su experiencia presente y la formulación emergente debe cambiar su percepción del problema de alguna manera. Por ejemplo, "nunca intenté invitar a una chica porque soy bajo. Todavía me asusta que una chica me llame "renacuajo" o algo así, pero estoy dispuesto a correr el riesgo ahora. Lo voy a hacer porque me he dado cuenta de que, aunque me lo diga, no me romperé. No me gustará mucho si lo hace, pero me sentiré mejor conmigo mismo si al menos lo intento." Algunos elementos de la estructura emergente pueden ser externos, conductuales o intelectuales, como la decisión de actuar de otra manera. Sin embargo, deben ser claramente solidarios con sentimientos inmediatos. Nunca resulta suficiente el constatar que una solución ha tenido lugar; las experiencias que recubren el proceso estructurante deben ser reveladas o revividas para satisfacer el criterio del nivel VI.

\section{Nivel VII}

El contendido revela la expansión del darse cuenta del comunicante respecto a sus sentimientos presentes e inmediatos y sus procesos internos. Él demuestra claramente que puede moverse de una referencia interna a otra alterando y modificando sus concepciones de sí mismo, sus sentimientos, sus reacciones privadas a sus pensamientos o acciones en términos de sus matices inmediatamente sentidos, como si ocurrieran en el momento experiencial presente, de forma que cada nuevo nivel de auto-darse cuenta funcione como un trampolín para futuras exploraciones. Las formulaciones acerca de sí en el nivel VII completan los requisitos del nivel VI con la condición adicional de que se aplica a un rango expandido de eventos internos, $o$ afloran a nuevas intuiciones. El desarrollo puede seguir uno de los siguientes modelos:

1. El comunicante puede comenzar con un problema anclado internamente, explorarlo y llegar a una conclusión fondeada en el interior que él aplica entonces a cierto número de otros problemas.

2. Puede llegar a soluciones relacionadas con un problema único y reintegrarlas. Cualquier auto-análisis se completa con una síntesis más comprensiva o extensiva.

3. El comunicante puede usar algunas formulaciones diferentes sobre sí mismo, cada una de las cuales contiene los requerimientos del estadio VI, e integra, relaciona o reduce esto a través de una formulación general más básica.

4. Puede comenzar con una conclusión del tipo avanzado del estadio VI y aplicarla a un rango diferente de situaciones, cada una con referentes internos explícitos, para mostrar cómo el principio general se aplica a un área extensa de su experiencia.

La experienciación en el estadio VII es expansiva, sin pliegues. El comunicante usa ágilmente una forma fresca de conocerse a sí mismo para expandir su experienciación más allá. La forma de estar en este nivel es frecuentemente eufórica, boyante o confidencial; el que habla comunica un sentir de las cosas que desemboca rápida y significativamente en algo. 


\section{Presentación de los resultados}

De acuerdo con los procedimientos ya descritos en la Metodología, se extrajeron de las 30 cartas de Julio Cortázar que contenían una referencia implícita o explícita a la obra Rayuela la totalidad de los párrafos en que esto ocurría, que alcanzaron la cifra de 139. Luego de ser transcritos fueron sometidos al escrutinio de dos jueces, que procedieron de modo independiente, a clasificar cada párrafo de acuerdo con los criterios de inclusión cualitativos de una escala de siete niveles, asignándolos al nivel que mejor describiera el funcionamiento y nivel de experienciar evidenciado por Cortázar en el texto.
Al comparar las clasificaciones de los jueces, se mantuvieron 17 divergencias en la asignación de párrafos a determinado nivel, las que al ser restadas de los 139 párrafos iniciales, determinaron que el análisis de resultados se hiciera sobre la base de los 122 párrafos en que hubo concordancia de clasificación entre los jueces.

La asignación de los párrafos a los distintos niveles permitió efectuar un análisis a partir de la estadistica descriptiva, presentando en forma global y cuantitativa el fenómeno cualitativo de la profundización experiencial de Julio Cortázar como correlato a la escritura de su obra Rayuela.

A continuación se ejemplifica cómo se realizó este análisis, ilustrándolo con párrafos representativos de cada uno de los siete niveles.

\section{Cuadro de análisis de $\mathrm{P}-\mathbf{0 7 8}$}

P-078 "El primero se deja leer en la forma corriente, y termina en el capítulo 56, al pie del cual hay tres vistosas estrellitas que equivalen a la palabra Fin. Por consiguiente, el lector prescindirá sin remordimientos de lo que sigue" (Cortázar, 1963c, p. 572).

\section{Acuerdo entre jueces ${ }^{\circ}$}

Nivell "La principal característica en este estado es que el contenido o la forma de expresión resultan impersonales... el contenido es intrínsecamente impersonal, siendo muy abstracto, general, superficial o un informe de acontecimientos o ideas sin referencia personal establecida" (Gendlin, 1969, p. 101).

\section{Cuadro de análisis de $P-112$}

P-112 "P. 617.- Han puesto "Gelio" a secas. Yo creo que puse Aulo Gelio, y que siempre se dice así. Si estás de acuerdo, agregálo” (Cortázar, 1963c, p. 576).

\section{Acuerdo entre jueces ${ }^{\circ}$}

Nivel II

"La asociación entre el que habla y el contenido es explícita. El
comunicante es ya la figura central de la narración o su interés re-
sulta claro. La implicación del que habla, sin embargo, no va más
allá de la situación específica o el contenido. Todos los comenta-
rios, asociaciones, reacciones y puntualizaciones sirven al relato o
idea para hacerse entender, pero no refieren o definen los senti-
mientos del comunicante" (Gendlin, 1969a, p. 102).

\section{Cuadro de análisis de $\mathbf{P}-021$}

P-021 "He puesto unas líneas destinadas al eventual impresor, para que entienda que lo que importa es la enumeración de los capítulos y no la paginación corriente (que he agregado a pie de página). Personalmente, yo creo que esta última paginación podría eliminarse, pero presumo que en la imprenta se van a agarrar la cabeza. ¿Vos qué pensás?” (Cortázar, 1962, pp. 482-483).

Acuerdo entre jueces ${ }^{\circ}$

Nivel III

" El contenido es una narración de eventos o descripción de un aspecto del medio ambiente del comunicante (pasado, presente o futuro), con puntualizaciones personales entre paréntesis [...]' (Gendlin, 1969a, p. 103). 
Cuadro de análisis de P-002

P-002 "Y eso es todo. La edición francesa de la novela está muy bonita, aunque con un precio tan astronómico que ni yo pienso comprarla. Me asombraría que tuviera el más pequeño éxito; pero lo mismo pensaba con respecto a la Argentina, y parece que me equivoqué. Entre tanto aproveché Viena para terminar la primera versión de La Rayuela, y al volver de mis vacaciones la trabajaré a fondo para que esté lista, si es posible, antes de fin de año. Lo que usted me diga de ella será muy importante para mí; ojalá encuentre la manera de hacerla copiar a máquina para mandarle un texto en noviembre o diciembre. Prepárese, son unas 700 páginas. Pero yo creo que ahí adentro hay tanta materia explosiva que tal vez no se haga tan largo leerla. De ilusiones así va uno viviendo" (Cortázar, 1961, p. 444).

\section{Acuerdo entre jueces ${ }^{\circ}$}

Nivel IV

"El contenido es un relato dicho desde un punto de vista completamente personal. Los detalles de sentimientos, reacciones y asunciones son integrados en la narrativa, de forma que lo que emerge es un cuadro detallado de la experiencia personal del comunicante sobre los eventos" (Gendlin, 1969a, p. 104).

\section{Cuadro de análisis de $\mathbf{P}-001$}

P-001 "Usted, que ya ha aludido más de una vez a mi lado "secreto", y que quisiera descifrarme un poco mejor a través de la lectura de mi novela, me conoce sin embargo mucho mejor que tanta gente que cree estar al corriente de mi vida y mis sentimientos y mis gustos o disgustos. Es cierto que soy discreto, y que la gente extravertida me molesta (por eso me molestan los españoles, como a usted, si no me equivoco). Pero en el fondo, Jean, lo que ocurre es que en mí no hay mucho de interesante, no hay mucho que mostrar ni que contar. No crea que me hago el interesante, o que peco de modesto. Lo que escribo es sobre todo invención, y es invención porque no tengo nada que recordar que valga la pena. Entonces, aprovechando un cierto don que me ha dado la naturaleza, invento, fabrico, extraigo "ex nihil". Gentes como Miller, Hemingway, Malraux, Céline, han vivido aventuras personales asombrosas, y con sólo contarlas bien ya tienen asegurada la admiración de los lectores. Yo, en cambio, me rompo un brazo, visito el Partenón, navego por el Ganges, pero siempre estoy como dentro de mí mismo; mis entusiasmos -que son grandes- no me arrancan del esteticismo o a lo sumo de una ansiedad de tono casi místico pero de calidad más que dudosa. Mi vida de joven fue igualmente anodina; amores opacos, violentas pasiones casi siempre injustificadas y por lo tanto rematadas en "queue de poisson", esperas, rebeldías sin mayor mérito... Ya ve que no es un curriculum vitae interesante. Usted cree que yo puedo quizá llegar a ser un novelista. Me falta, como me dice, "un peu de souffle pour aller jusqu'au bout".' Pero aquí, Jean, intervienen otras razones, y éstas estrictamente intelectuales y estéticas. La verdad, la triste o hermosa verdad, es que cada vez me gustan menos las novelas, el arte novelesco tal como se lo practica en estos tiempos. Lo que estoy escribiendo ahora ${ }^{2}$ será (si lo termino alguna vez) algo así como una antinovela, la tentativa de romper los moldes en que se petrifica ese género. Yo creo que la novela "psicológica" ha llegado a su término, y que si hemos de seguir escribiendo cosas que valgan la pena, hay que arrancar en otra dirección. El surrealismo marcó en su momento algunos caminos, pero se quedó en la fase pintoresca. Es cierto que no podemos ya prescindir de la psicología, de los personajes explorados minuciosamente; pero la técnica de los Michel Butor y las Nathalie Sarraute me aburren profundamente. Se quedan en la psicología exterior, aunque crean ir muy al fondo. El fondo de un hombre es el uso que haga de su libertad. Por ahí se va a la acción y a la visión, al héroe y al místico. No quiero decir que la novela deba proponerse esta clase de personajes, porque los únicos héroes y místicos interesantes son los vivientes, no los inventados por un novelista. Lo que creo es que la realidad cotidiana en que creemos vivir es apenas el borde de una fabulosa realidad reconquistable, y que la novela, como la poesía, el amor y la acción, deben proponerse penetrar en esa realidad. Ahora bien, y esto es lo importante: para quebrar esa cáscara de costumbres y vida cotidiana, los instrumentos literarios usuales ya no sirven. Piense en el lenguaje que tuvo que usar un Rimbaud para abrirse paso en su aventura espiritual. Piense en ciertos versos de Les Chimères de Nerval. Piense en algunos capítulos de Ulysses. ¿Cómo escribir una novela cuando primero habría que des-escribirse, des-aprenderse, partir "à neuf", desde cero, en una condición pre-adamita, por decirlo así? Mi problema, hoy en día, es un problema de escritura, porque las herramientas con las que he escrito mis cuentos ya no me sirven para esto que quisiera hacer antes de morirme. Y por eso -es justo que usted lo sepa desde ahora-, muchos lectores que aprecian mis cuentos habrán 
de llevarse una amarga desilusión si alguna vez termino y publico esto en que estoy metido. Un cuento es una estructura, pero ahora tengo que desestructurarme para ver de alcanzar, no sé cómo, otra estructura más real y verdadera; un cuento es un sistema cerrado y perfecto, la serpiente mordiéndose la cola; y yo quiero acabar con los sistemas y las relojerías para ver de bajar al laboratorio central y participar, si tengo fuerzas, en la raíz que prescinde de órdenes y sistemas. En suma, Jean, que renuncio a un mundo estético para tratar de entrar en un mundo poético. ¿Me hago ilusiones, terminaré escribiendo un libro o varios libros que serán siempre míos, es decir con mi tono, mi estilo, mis invenciones? A lo mejor sí. Pero habré jugado lealmente, y lo que salga será así porque no puedo hacer otra cosa. Si hoy siguiera escribiendo cuentos fantásticos me sentiría un perfecto estafador; modestia aparte, ya me resulta demasiado fácil, "je tiens le système", como decía Rimbaud. Por eso "El perseguidor"es diferente, y usted habrá pensado en él al leer estas líneas tan confusas. Ahí ya andaba yo buscando la otra puerta. Pero todo es tan oscuro, y yo soy tan poco capaz de romper con tanto hábito, tanta comodidad mental y física, tanto mate a las cuatro y cine a las nueve... Para subir a la Santa Maria y poner proa al misterio hay que empezar por tirar la yerba a la basura. Y con este mal anacronismo cierro este capitulo que sin embargo estoy contento de haber escrito para usted, como una confidencia y un anuncio" (Cortázar, 1959, pp. 396-397).

\section{Notas}

${ }^{1}$ Un poco de aliento para llegar hasta el final.

2 "Rayuela".

\section{Acuerdo entre jueces}

Nivel V

"[...] el comunicante debe plantear o definir un problema o una proposición acerca de sí mismo explícitamente en términos de sentimientos. El problema o proposición puede recoger el origen, secuencia o implicaciones de sentimientos, o sentimientos relacionados con otros procesos privados. Segundo, el comunicante debe explorar o trabajar con un problema de una forma personal. La exploración o elaboración debe estar claramente relacionada con la proposición inicial, y debe contener referencias internas de forma que funcione expandiendo el darse cuenta del comunicante sobre la experienciación. Ambos componentes, problema y elaboración, deben estar presentes" (Gendlin, 1969a, p. 105).

\section{Cuadro de análisis de $\mathbf{P}-\mathbf{0 4 3}$}

P-043 "El texto que vos preparaste para la solapa tiene dos párrafos. El primero no me gusta tanto como el segundo. Sobre todo la primera frase me suena dura y complicada. En realidad creo que convendría cambiar esa primera frase, y utilizar el resto tal como lo has redactado. Te propongo sustituir el primer párrafo por algo así:

"Los personajes de Rayuela asisten a su propia derrota con una ironía en la que se adivina, quizá, un triunfo secreto. En el vago territorio en que se mueven, donde el amor, los celos y la piedad parecen obedecer demoníacamente a un signo contrario, la causalidad psicológica cede desconcertada, las criaturas se encuentran y se desencuentran sin sospechar demasiado que en cada una de las figuras que forman su danza hay un acercamiento a la mutación final: la última casilla de la rayuela, el Igdrassil, el centro del mandala" (Cortázar, 1963b, pp. 536-537).

Nivel VI Acuerdo entre jueces ${ }^{\circ}$

"El contenido es una síntesis de sentimientos y experiencias bastante accesibles, reconocidas de forma nueva o realizadas más plenamente, en orden a producir estructuras significativas personalmente o para resolver temas (Gendlin, 1969a, p. 102). 


\section{Cuadro de análisis de P-008}

P-008 "En realidad tengo tantas cosas que decirte que no sé por dónde empezar. Yo mismo estoy abrumado por la ambición del libro, y por lo que en algunos momentos llega a conseguir. Es realmente uno de esos despelotes que solamente de tiempo en tiempo, no te parece. He tenido que vigilar cuidadosamente mis reacciones mientras corregía, porque más de una vez he sentido que se hubiera salido ganando de acortar, o suprimir determinados capítulos o pasajes. Pero cada vez me he dado cuenta de que al pensar eso, quien lo pensaba era "el hombre viejo", es decir que era, una vez más, una reacción estética, literaria. Una reacción en nombre de ciertos valores formales que hacen la gran literatura. $Y$ vos ya conocés lo bastante a Morelli para saber que el viejo lo que quiere es hacer polvo esos valores porque le parecen la máscara podrida de un orden de cosas todavía más podrido" (Cortázar, 1962a, p. 466).

\section{Nivel VII}

\section{Acuerdo entre jueces ${ }^{\circ}$}

"El contendido revela la expansión del darse cuenta del comunicante respecto a sus presentes e inmediatos sentimientos y sus procesos internos. Él demuestra claramente que puede moverse de una referencia interna a otra alternando y modificando sus concepciones de sí mismo, sus sentimientos, sus reacciones privadas a sus pensamientos o acciones en términos de sus matices inmediatamente sentidos, como si ocurrieran en el momento experiencial presente, de forma que cada nuevo nivel de auto-darse cuenta funcione como un trampolín para futuras exploraciones" (Gendlin, 1969a, p. 107). 


\section{Análisis e Interpretación de los Resultados}

Cuadro Resumen: Número y porcentaje de párrafos clasificados de modo concordante y discordante entre los jueces

\begin{tabular}{|c|c|c|c|c|}
\hline \multirow[t]{2}{*}{ Nivel } & \multicolumn{2}{|c|}{$\begin{array}{l}\text { Párrafos clasificados } \\
\text { concordantemente en- } \\
\text { tre los jueces }\end{array}$} & \multicolumn{2}{|c|}{$\begin{array}{l}\text { Párrafos clasificados } \\
\text { discordantemente entre } \\
\text { los jueces }\end{array}$} \\
\hline & Número & Porcentaje & Número & Porcentaje \\
\hline $\begin{array}{l}\text { I. No se usa referencia alguna. Narración de even- } \\
\text { tos de forma pública y desde afuera. Negativa de } \\
\text { implicación personal. }\end{array}$ & 16 & $13,11 \%$ & 3 & $17,64 \%$ \\
\hline $\begin{array}{l}\text { II. Los referentes personales se utilizan para esta- } \\
\text { blecer claramente que se trata de su historia. }\end{array}$ & 21 & $17,21 \%$ & 1 & $5,88 \%$ \\
\hline $\begin{array}{l}\text { III. La utilización y expresión de emociones se reali- } \\
\text { za tangencialmente, a modo de paréntesis en la na- } \\
\text { rración. Aun así, los sentimientos personales todavía } \\
\text { están: (a) completamente atados a las situaciones en } \\
\text { las que aparecen. (b) Sin elaborar en términos de sig- } \\
\text { nificado personal más profundo o significación. }\end{array}$ & 23 & $18,85 \%$ & 2 & $11,76 \%$ \\
\hline $\begin{array}{l}\text { IV. Se da de distintas formas: Expresión fluida de } \\
\text { muchos sentimientos; expresión de un solo sentimien- } \\
\text { to, en el que el cliente se toma su tiempo para elabo- } \\
\text { rarlo en términos de significado de auto-imagen; ex- } \\
\text { presión o comunicación de que el sentimiento exis- } \\
\text { te, pero se necesita ayuda para expresarlo mejor. }\end{array}$ & 53 & $43,44 \%$ & 4 & $23,52 \%$ \\
\hline $\begin{array}{l}\text { V. Exploración de: (a) una sola situación relevante a } \\
\text { la autoimagen, que a su vez implica muchos senti- } \\
\text { mientos y consecuentes relaciones, o también la des- } \\
\text { cripción de un área de sentimientos con el significa- } \\
\text { do personal consecuente; (b) examen y exploración } \\
\text { de varias situaciones y sus puntos en común. }\end{array}$ & 1 & $0,82 \%$ & 1 & $5,88 \%$ \\
\hline $\begin{array}{l}\text { VI. Los sentimientos se integran. Existencia de aso- } \\
\text { ciaciones entre sentimientos y los significados per- } \\
\text { sonales. }\end{array}$ & 3 & $2,46 \%$ & 1 & $5,88 \%$ \\
\hline $\begin{array}{l}\text { VII. El cliente ya no necesita la narración como pun- } \\
\text { to de partida. Ya es capaz de moverse libremente a } \\
\text { través de sus sentimientos. Ya no existe dificultad } \\
\text { alguna en relacionar lo que él dice con los signifi- } \\
\text { cados que sus acciones y pensamientos tienen para } \\
\text { él. Se mueve fácilmente a través de sus referencias } \\
\text { interiores y es capaz de integrarlas dentro de su } \\
\text { marco de referencia existencial. }\end{array}$ & 5 & $4,09 \%$ & 5 & $29,41 \%$ \\
\hline TOTAL & 122 & $100 \%$ & 17 & $100 \%$ \\
\hline
\end{tabular}


Gráfico $\mathrm{N}^{\circ} 1$ : Porcentaje de parráfos clasificados en cada nivel de la escala experiencial

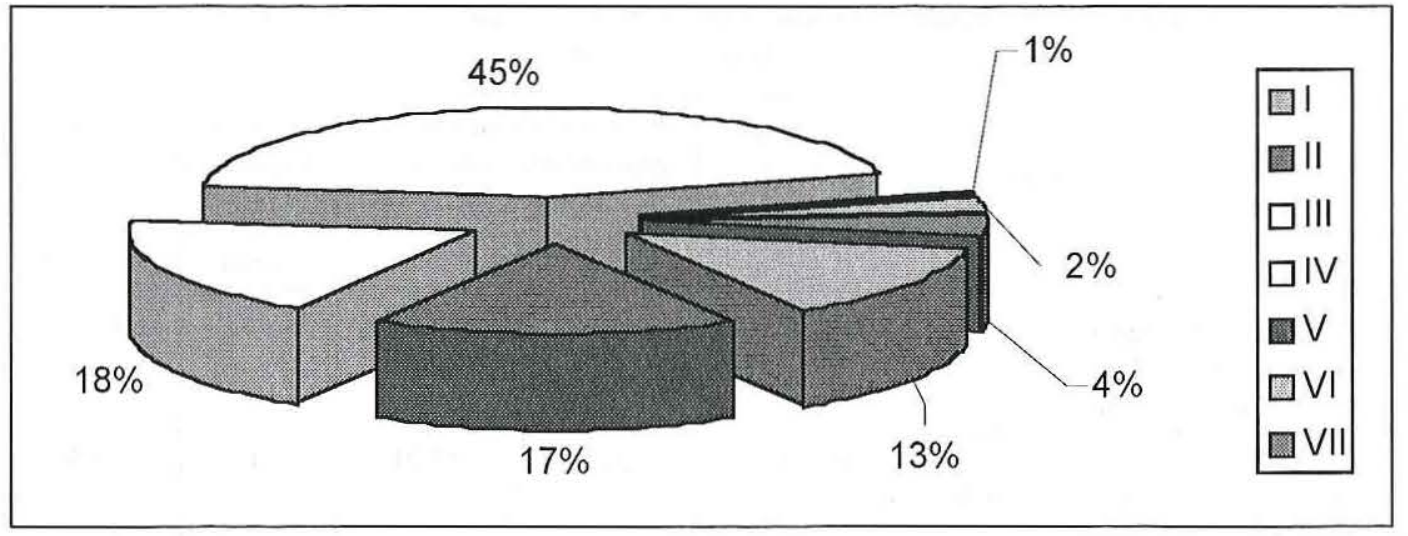

El escritor Julio Cortázar como correlato a la escritura de la obra Rayuela muestra un $45 \%$ $(43,65 \%)$ de párrafos clasificados en un Nivel IV. Desde el punto de vista del contenido, se caracteriza como: una "expresión fluida de muchos sentimientos; expresión de un solo sentimiento [...] para elaborarlo en términos de significado de autoimagen; expresión o comunicación de que el sentimiento existe [...]" (Gendlin, 1969a, p. 108). Desde el punto de vista de la forma, el escritor comunica "lo que es él mismo" tal como se percibe a sí en el experienciar (Gendlin, 1969a).

Un 19\% (18,25\%) de los párrafos fueron clasificados en un Nivel III. El contenido denota una característica sustancial: "la utilización y expresión de emociones se realiza tangencialmente, a modo de paréntesis en la narración. Aun así, los sentimientos personales todavía están: (a) completamente atados a las situaciones en las que aparecen. (b) Sin elaborar en términos de significado personal más profundo o significación" (Gendlin, 1969a, p.108). Desde el punto de vista de la forma, existe una "implicación personal más allá del contenido específico, pero sin conseguir significados más profundos" (Gendlin, 1969a, p. 108).

Un $17 \%(17,46 \%)$ de los párrafos se clasificaron en un Nivel II. El contenido del experienciar de Cortázar muestra que los referentes personales se utilizaron por el escritor para clarificar que lo narrado se trataba de su propia historia. Si apreciamos la forma, muestra que existe una "implicación personal" en lo narrado (Gendlin, 1969a).

Un 13\% (13,49\%) de los párrafos fueron clasificados en un Nivel I. El contenido se caracteriza porque en ellos el escritor narra los eventos "de forma pública y desde afuera". Existe una clara "negativa de implicación personal". La forma de lo narrado por el autor denota la "inexistencia de una implicación personal" (Gendlin, 1969a, p.108).

Un 4\% $(3,96 \%)$ de los párrafos fueron clasificados en un Nivel VII. El contenido en ellos denota a un Julio Cortázar que "[...] ya no necesita la narración como punto de partida. Ya es capaz de moverse libremente a través de sus sentimientos. Ya no existe dificultad alguna en relacionar lo que él dice con los significados que sus acciones y pensamientos tienen para él. Se mueve fácilmente a través de sus referencias interiores y es capaz de integrarlas dentro de su marco de referencia existencial" (Gendlin, 1969a, p.108). Por la forma de estas narraciones el autor demuestra que se ha contactado con su experienciar, utilizando "[...] un marco existencial de referencia, [desde el cual se] produce una libertad interior de movimiento en cuanto a los sentimientos y sus significados" (Gendlin, 1969a, p.108).

Un $2 \%(2,38 \%)$ de los párrafos fueron clasificados en un Nivel VI. Considerando el contenido, Julio Cortázar integra sus sentimientos: asociándolos entre sí y los significados personales. La perspectiva de la forma muestra que el escritor "[...] es capaz de llegar a conclusiones surgidas a raíz de intuiciones producidas por el hallazgo de significados en los sentimientos" (Gendlin, 1969a, p. 108).

Un $1 \%(0,79)$ de los párrafos fueron clasificados en un Nivel V. Al centrarnos en el contenido, Julio Cortázar narra efectuando una "exploración de: (a) una sola situación relevante a la autoimagen, que a su vez implica muchos 
sentimientos y consecuentes relaciones, o también la descripción de un área de sentimientos con el significado personal consecuente; (b) examen y exploración de varias situaciones y sus puntos en común" (Gendlin, 1969a, p.108). Si nos centramos en la forma, en la cualidad formal de lo narrado por el autor se aprecia que realiza una "definición del problema en términos de sentimientos e intento de exploración de los mismos" (Gendlin, 1969a, p.108).

\section{Concordancia y discordancia entre los jueces}

$\mathrm{Al}$ proponer una metodología para el estudio de la profundización experiencial en Julio Cortázar, el trabajo de clasificación de los párrafos en determinados niveles de la Escala Experiencial, ha producido concordancias y discordancias entre los jueces, las cuales son importantes de tener en cuenta, ya que entregan una información directamente relacionada con uno de los objetivos de la investigación: "Apor- tar al desarrollo de un enfoque Humanista para el estudio de la profundización experiencial como correlato del acto creativo". Al considerar los datos provenientes de la concordancia y la discordancia de las clasificaciones entre los jueces, puede establecerse cuáles son resultados logrados por la metodología propuesta para el estudio de la "profundización experiencial", a partir de un análisis comparado entre las clasificaciones; lo cual resulta importante, pues al tratarse de un estudio exploratorio, los datos que se recojan serán indicadores de la precisión de la metodología para "aportar al desarrollo del grado de pertinencia que puede tener la escala experiencial de Gendlin en un ámbito no clínico", logrando así "aportar al desarrollo de un enfoque humanista para el estudio de la profundización experiencial como correlato del acto creativo".

A continuación se ejemplifica con un caso de discrepancia entre los jueces. 


\section{Cuadro de análisis de P-041}

$\mathrm{P}-041$ "Te agradezco mucho tus palabras tan afectuosas en lo que concierne a mis preocupaciones familiares. Aunque yo estaba preparado desde hace mucho para la muerte de mi abuela, la noticia me trajo ese desgarramiento en el que por un momento uno se ve realmente como es, y los fantasmas danzan su ronda y toda la vida se agolpa y acusa y condena, y te vuelve como un testigo de vos mismo. Ya pasó, claro está, y me queda el consuelo de pensar que ese largo e inmerecido sufrir de tantos meses ha terminado como tenía que terminar. Curiosamente, la carta de mi madre en la que me daba la noticia, llegó junto con el paquete de las pruebas de Rayuela. Yo, que a todo le veo un sentido figurado, extraje mis conclusiones y cociné minuciosamente mis insomnios de varias noches. Y después me puse a trabajar, y las cosas se fueron ordenando lentamente. Tus cartas me hicieron mucho bien, como siempre, porque te sentí muy próximo. En la última, me llenó de entusiasmo tu gran alegría frente a tu película. Cuando decís: "Qué patada a los estúpidos que me ha salido", me parece la más perfecta definición de vos mismo, de lo que te has propuesto hacer. Y qué bueno es que estés contento de la película, que hayas conseguido hacer lo que te proponías. Supongo que ya la habrás visto completa, porque me decías en una de tus cartas que aún no la habían proyectado con música y ruidos. Ahora sabrás lo que es ver en carne y hueso a las criaturas de tu imaginación. Y si sentís lo que sentí yo cuando vi a Nico, a Luis y a Laura, creo que te sentirás muy feliz" (Cortázar, 1963a, p. 533).

\begin{tabular}{|c|c|c|c|}
\hline \multicolumn{4}{|c|}{ Desacuerdo entre jueces ${ }^{\circ}$} \\
\hline JUEZ "A" & & JUEZ "B" & \\
\hline Nivel VI & $\begin{array}{l}\text { "El contenido es una sintesis de sen- } \\
\text { timientos y experiencias bastante } \\
\text { accesibles, reconocidas de forma } \\
\text { nueva o realizadas más plenamen- } \\
\text { te, en orden a producir estructuras } \\
\text { significativas personalmente [...] } \\
\text { Los sentimientos más inmediatos } \\
\text { del comunicante son integrados con } \\
\text { sus conclusiones sobre sus tareas in- } \\
\text { ternas. Él comunica una auto- } \\
\text { experienciación nueva o enriqueci- } \\
\text { da, y el impacto de las experiencias } \\
\text { de los cambios en sus actitudes o } \\
\text { sentimientos acerca de sí mismo. El } \\
\text { objeto del asunto concierne al } \\
\text { experienciar presente y emergente } \\
\text { del comunicante. Su asunto puede } \\
\text { reflejar cambios o intuiciones en el } \\
\text { momento en que ocurren. Estas son } \\
\text { elaboradas verbalmente con detalle. } \\
\text { Aparte del contenido específico, el } \\
\text { comunicante expresa un sentido de } \\
\text { involucración inmediata en un tema } \\
\text { fondeado experiencialmente, con } \\
\text { evidencia de su resolución o acep- } \\
\text { tación" (Gendlin, 1969a, p. 106). }\end{array}$ & Nivel VII & $\begin{array}{l}\text { "El contendido revela la expansión } \\
\text { del darse cuenta del comunicante } \\
\text { respecto a sus presentes e inmedia- } \\
\text { tos sentimientos y sus procesos in- } \\
\text { ternos [...] La experienciación en el } \\
\text { estadio [...] es expansiva, sin plie- } \\
\text { gues. El comunicante usa ágilmen- } \\
\text { te una forma fresca de conocerse a } \\
\text { sí mismo para expandir su } \\
\text { experienciación más allá. La forma } \\
\text { de estar en este nivel es frecuente- } \\
\text { mente eufórica, boyante o confiden- } \\
\text { cial; el que habla comunica un sen- } \\
\text { tir de las cosas que desemboca rá- } \\
\text { pida y significativamente en algo" } \\
\text { (Gendlin, 1969a, pp. 107-108). }\end{array}$ \\
\hline
\end{tabular}


Gráfico $\mathrm{N}^{\circ} 2$ : Porcentaje de párrafos clasificados de modo concordante y discordante entre los jueces

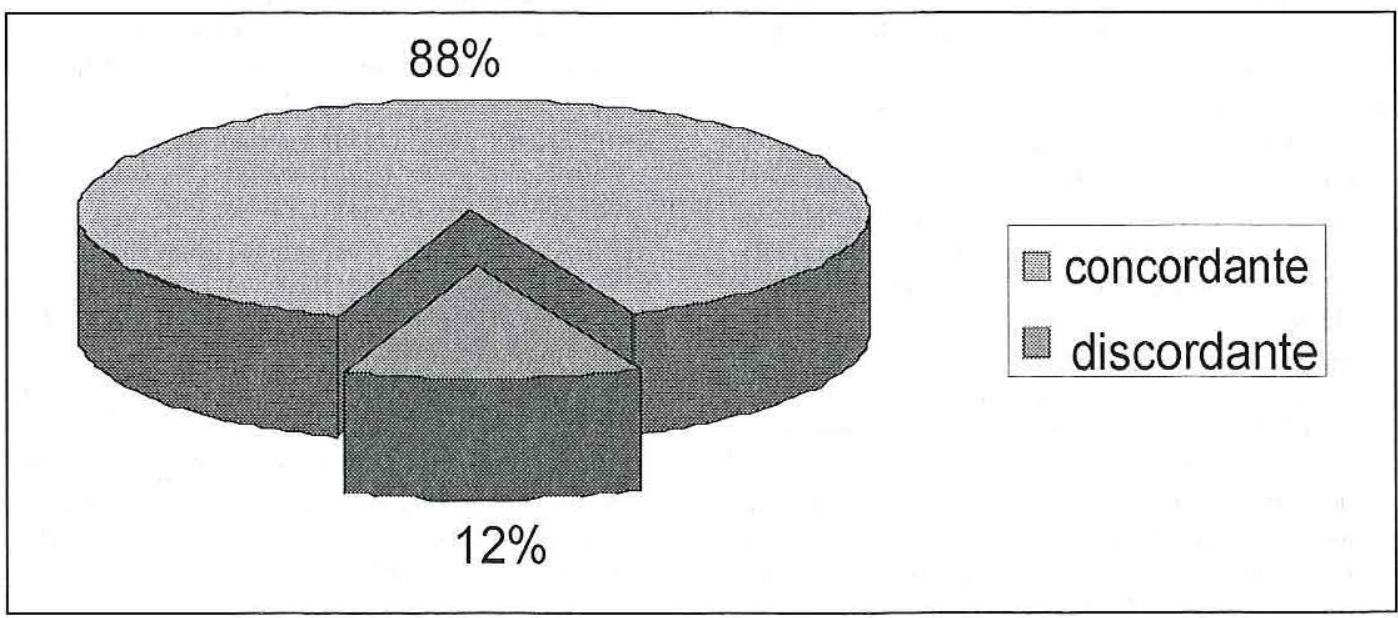

Los jueces concordaron en la clasificación de 122 de los 139 párrafos, lo que significa que coincidieron en clasificar en un mismo nivel al $87,77 \%$ de los párrafos y que discreparon sólo en $17(12,23 \%)$ de las asignaciones, según los criterios de inclusión cualitativos de la Forma Explicativa de la Escala Experiencial de Eugene T. Gendlin. Estos resultados sugieren dos cosas importantes. La primera, que el autor estudiado muestra en su comportamiento verbal escrito referencias que permiten a ambos jueces clasificarlas consistentemente de un mismo modo, según logran apreciar las diferentes funciones y niveles de su experienciar: La metodología propuesta al mostrar tal número de clasificaciones convergentes entre los jueces, constituye un aporte, en tanto pone en evidencia que el instrumento es confiable (Nunnally, 1973), pudiendo ser utilizado para definir los comportamientos verbales que ocurren en un contexto distinto al psicoterapéutico y oral, apuntando en dirección a su validez (Nunnally, 1973).

\section{Conclusiones}

Mediante la investigación efectuada ha sido posible establecer la relación que existe entre la profundización experiencial y el acto creativo. El autor Eugene T. Gendlin establece tal nexo mediante la formulación de un constructo: la sensación-sentida, que al llevar el experienciar hacia adelante, se transforma en un emergente de nuevos pensamientos, sentimientos, significaciones y soluciones que no son posibles de ninguna otra manera (Gendlin, 1981). Por las características de este proceso, puede asociarse al acto creativo de escritura de la obra Rayuela, centrándonos en la subjetividad de su autor, evidenciada en el registro epistolar.

Los resultados obtenidos con la utilización de la Escala Experiencial Forma Explicativa sugieren que es un instrumento susceptible de ser extrapolado a contextos no-clínicos (no-psicoterapéuticos). En particular, resulta pertinente para el análisis de párrafos epistolares, logrando dar cuenta, de la profundización experiencial de Julio Cortázar como correlato a la escritura de la obra Rayuela, apuntando con ello. En dirección a su validez, es decir, mide lo que dice medir (Nunnally, 1973) en este nuevo ámbito.

La elevada concordancia producto de clasificaciones convergentes entre los jueces señala que el instrumento posee buena confiabilidad, o sea, es preciso en la medición (Nunnally, 1973), mostrando que la metodología propuesta para el análisis de los párrafos es pertinente y susceptible de ser aplicada como una herramienta de análisis para describir la subjetividad de escritores como correlato al acto de creación de obras consideradas importantes para la literatura.

\section{Referencias}

CORTÁZAR, J. (1959). A Jean Bernabé. [París, 27 de Junio de 1959]. En: Bernárdez, A. (Ed.). Cartas (1937-1963). (Vol. 1). (pp. 394-398). Buenos Aires: Alfaguara, 2000.

CORTÁZAR, J. (1961). A Francisco Porrúa. [París, 23 de Mayo de 1961]. En: Bernárdez,A. (Ed.). Cartas (1937-1963). (Vol. 1). (pp. 443-445). Buenos Aires: Alfaguara, 2000.

CORTÁZAR, J. (1962a). A Francisco Porrúa. [París, 5 de Enero de 1962]. En: Bernárdez, A. (Ed.). Cartas (19371963). (Vol. 1). (pp. 465-468). Buenos Aires: Alfaguara, 2000. 


\section{CRISTIAN VENEGAS}

CORTÁZAR, J. (1962b). A Francisco Porrúa. [París, 30 de Mayo de 1962]. En: Bernárdez, A. (Ed.). Cartas (1937-1963). (Vol. 1). (pp. 482-484). Buenos Aires: Alfaguara, 2000.

CORTÁZAR, J. (1963a). A Manuel Antín. [París, 6 de Enero de 1963]. En: Bernárdez, A. (Ed.). Cartas (1937-1963). (Vol. 1). (pp. 533-535). Buenos Aires: Alfaguara, 2000.

CORTÁZAR, J. (1963b). A Francisco Porrúa. [París, 22 de Febrero de 1963]. En: Bernárdez, A. (Ed.). Cartas (19371963). (Vol. 1). (pp. 536-537). Buenos Aires: Alfaguara, 2000.

CORTÁZAR, J. (1963c). A Francisco Porrúa. [París, 21 de Mayo de 1963]. En: Bernárdez, A. (Ed.). Cartas (1937-1963). (Vol. 1). (pp. 572-579). Buenos Aires: Alfaguara, 2000.

GENDLIN, E. (1969a). La Escala Experiencial. En: Alemany, C. (Ed.). Psicoterapia experiencial y focusing. La aportación de E. T. Gendlin (pp. 101-108). Bilbao: Desclée de Brouwer, 1997.

GENDLIN, E. (1969b). Focusing. En: Alemany, C. (Ed.). Psicoterapia experiencial y focusing. La aportación de $E$. $T$. Gendlin (pp. 109-124). Bilbao: Desclée de Brouwer, 1997.

GENDLIN, E. (1981). Focusig y el desarrollo de la creatividad. En: Alemany, C. (Ed.). Psicoterapia experiencial y focusing. La aportación de E. T. Gendlin (pp. 237-240). Bilbao: Desclée de Brouwer, 1997.

GENDLIN, E. (1997). Prefacio. En: Alemany, C. (Ed.). Psicoterapia experiencial y focusing. La aportación de E. T. Gendlin (pp. 21-30). Bilbao: Desclée de Brouwer, 1997.
HERNÁNDEZ, R. FERNÁNDEZ, C. \& BAPTISTA, P. (1991). Definición del tipo de investigación a realizar: básicamente exploratoria, descriptiva, correlacional o explicativa. En: Melodología de la investigación (pp. 5771). México: Mc Graw Hill, 1998.

KRIPPENDORFF, K. (1980). Fundamentos conceptuales. En: Metodología de Análisis de contenido. Teoría y práctica. (pp. 28-44). Barcelona: Paidós, 1997.

NUNNALLY, J. (1973). Confiabilidad de las mediciones. / Validez de los métodos de medición. En: Introducción a la medición en Psicología (pp. 131-157 / pp. 158-180) Buenos Aires: Paidós, 1973.

PERCIVAL, A. (1987). El lector en Rayuela. En: Rall, D. (Compl.). En busca del texto. Teoría de la recepción literaria (pp. 381-397). México: Ciudad Universitaria, 1987.

SARTRE, J-P. (1943). Introducción. En busca del ser. La idea de fenómeno. En: El Sery la Nada (pp.11-14). Buenos Aires: Losada, 1993.

SEGRE, C. (1985). El autor. En: Principios de análisis del texto literario (p. 14). Barcelona: Crítica, 1985.

STAKE, R. (1995). El caso único. En: Investigación con estudio de casos (pp.15-24). Madrid: Morata, 1999.

VAN DUSEN, W. (1975). La fenomenología de una existencia esquizofrénica. En: Stevens, J. (Ed.). Esto es Guestalt. Colección de artículos sobre terapia y estilos de vida guestálticos (pp. 99-114). Santiago: Cuatro Vientos, 1991. 